\title{
MEDINDO NA CASA A CONCENTRACIÓN DUNHA DISOLUCIÓN CON SOLUTO GASOSO
}

\author{
Cid Manzano, R. \\ VALIÑA LEMA, I. \\ IES de Curtis (A Coruña)
}

\section{INTRODUCIÓN}

As actividades experimentais conectadas co currículo escolar realizadas polo alumnado nas súas casas non son só un complemento ás levadas a cabo no centro escolar-suplindo as máis das veces a falta de tempo nas materias de ciencias nalgúns cursos da secundaria obrigatoria - senón que en si mesmo poden chegar a ser para os estudantes enormemente enriquecedoras en si mesmas en termos de aprendizaxe.

Presentamos aquí un traballo experimental proposto ao alumnado de $3^{\circ}$ da ESO na materia de Física e Química consistente en medir nas súas casas a concentración de dióxido de carbono nun refresco carbonatado, e vendo como varía a súa concentración co tempo e a temperatura. Esta actividade formou parte dun grupo de traballos procedimentais voluntarios formulados a este alumnado durante o confinamento pola pandemia da Covid-19, aínda que tamén forma parte dunha estratexia habitual para os contidos procedimentais neste curso, debido a que só se conta con dúas sesións lectivas por semana.

A acción aquí presentada ten unha tripla implicación, pois dunha parte permite abordar un contido moi importante no currículo de Física e Química, como é a medida de concentracións de disolucións; doutra, implica a presenza dun soluto gasoso, que non é nada habitual para este tipo de actividades; e en terceiro lugar está o contexto, xa que aborda un asunto cercano ao alumnado, como a cantidade de gas que ten un refresco (que é unha das súas propiedades máis características) e como depende ela da temperatura e o tempo. 


\section{FUNDAMENTACIÓN}

A idea de presentar esta actividade neste artigo procede de considerar que cumpre coas cualidades que son propias da competencia científica. Ademais, os procedementos a seguir están en clara concordancia coas estratexias didácticas de indagación, argumentación e uso de probas, que son bases esenciais para a consecución dunha verdadeira aprendizaxe significativa, e, finalmente, presenta un certo grao de conexión coa chamada ciencia recreativa, que aporta a súa propia dimensión didáctica.

Nesta acción concítanse as cinco funcións que debe ter un traballo práctico (Caamaño, 2005): (a) función ilustrativa dos conceptos, (b) función interpretativa das experiencias, (c) función de aprendizaxe de métodos e técnicas de laboratorio, (d) función investigativa teórica relacionada coa resolución de problemas teóricos e construción de modelos, e (e) función investigativa práctica relacionada coa resolución de problemas prácticos.

Se falamos en termos de competencia científica, incluímos este tipo de experiencias como estratexia, pois, seguindo a definición desa competencia, implica utilizar o coñecemento científico e aplicar os procedementos da ciencia en contextos cotiás, sendo consciente do papel da ciencia e a tecnoloxía na sociedade, na solución e a orixe dos problemas, así como mostrar interese, reflexionar e comprometerse coas cuestiones científicas e tecnolóxicas, desde unha perspectiva persoal e social. Pódese estruturar en catro dimensións básicas: contexto, destrezas, conceptos e actitudes (Caamaño, 2011).

Por outra parte, este tipo de accións a realizar na casa polo alumnado presenta a característica concreta do que se vén chamando ciencia recreativa, que presenta a súa propia dimensión didáctica (García-Molina, 2011) como ferramenta de motivación, medio para captar a atención, e como recurso para a introdución de conceptos, superando as habituais canles da divulgación (revistas, televisión, conferencias, feiras da ciencia, museos, etc).

Finalmente, e dentro dos enfoques CTS para o ensino das ciencias, partimos do contexto para introducir e desenvolver os conceptos e os modelos. Este enfoque baseado no contexto toma en consideración os ámbitos próximos ao alumnado, pero non só como inicio senón tamén como conclusión, xa que o que o/a estudante aprende no contexto pode aplicalo despois no mesmo (Catret et al., 2013).

\section{DESENVOLVEMENTO}

0 procedemento experimental é moi sinxelo e ten como principio esencial a medida da masa de dióxido de carbono nun refresco de cola por diferenzas de pesada, pero hai varias consideracións iniciais que debemos ter en conta para nos enfrontar debidamente aos procedementos.

0 primeiro que hai que indicar é que o alumnado debe usar unha balanza na casa cunha precisión mínima de 0,1 g. Isto, que podería en principio ser un problema, pode solucionarse coas balanzas dixitais de baixo custo que temos nos laboratorios dos centros, mediante unha rotación deses aparatos entre o alumnado participante (lémbrese que estes experimentos forman parte dun conxunto deles a realizar polo alumnado de xeito voluntario). Ademais, hai no mercado este tipo 
de balanzas con custos de arredor dos dez euros, polo que este condicionante non representa algo especialmente complicado nin para o alumnado nin para os departamentos de Física e Química, no caso de que se optase por realizar unha compra destas balanzas.

Unha segunda consideración ten que ver cos destinatarios da experiencia. Aínda que se sinalou ao comezo que estaba dirixido ao alumnado de $3^{\circ}$ da ESO polo reducido do seu horario na materia, é evidente que se pode estender en parte, ou na súa totalidade, e mesmo con ampliacións, ao resto dos cursos tanto da ESO como do Bacharelato, pois se trata duns contidos tanto conceptuais como procedimentais que forman parte dos currículos de Física e Química de calquera curso de secundaria. Aínda máis, estes procedementos, cos seus cálculos e procesos máis simples, son tamén asequibles para os últimos cursos de ensino primario na área de Ciencias da Natureza.

A partir dos procedementos que se describen deseguido, baseados en diferenzas de pesada, poderán os alumnos e alumnas expresar as concentracións do gas carbónico nas diferentes unidades que son obxecto de interese nos currículos respectivos.

Hai que ter presente que ademais de $\mathrm{CO}_{2}$ haberá na disolución outros gases como $\mathrm{N}_{2}$ e $\mathrm{O}_{2}$ pero en cantidades moito máis pequenas, polo que só consideraremos nos cálculos que é o gas carbónico o que se desprende durante os procedementos. Naturalmente, por moito coidado que poñamos haberá certas cantidades deste gas que van escapar das medidas, habendo, ademais, un equilibrio $\mathrm{CO}_{2} / \mathrm{H}_{2} \mathrm{CO}_{3}$ presente no medio acuoso. Con todo, o importante aquí é que o alumnado realice as medidas, faga os cálculos, obteña resultados que estean dentro do intervalo de valores esperados, e exprese correctamente eses resultados.

Tamén podemos considerar que dependendo da temperatura, o que ten máis importancia no segundo dos procedementos que presentamos, tamén hai evaporación de auga. Como veremos, podemos minimizar este aspecto traballando con refrescos tomados da neveira $\left(4{ }^{\circ} \mathrm{C}-10^{\circ} \mathrm{C}\right) \mathrm{e}$ mesmo a $0 \stackrel{\circ}{\circ}$ controlando esta temperatura cun baño de auga líquida/xeo.

Por outra parte, debemos ter coidado co peso (masa) das latas de aluminio, no caso de que queramos traballar con este dato, pois dependendo do lote do que se trate poden presentar diferenzas de case $0,5 \mathrm{~g}$, o que é significativo dados os valores baixos de masa de gas carbónico que están presentes. Por exemplo, na nosa experimentación temos traballado con latas de 12,4 g, 12,5 g e $12,7 \mathrm{~g}$.

Tampouco é fácil coñecer a cantidade exacta de dióxido de carbono por litro que presentan estas bebidas a fin de ter unha información de partida inicial, pois é lixeiramente diferente en función do tipo de refresco, do país e da empresa envasadora. Con todo, tomaremos como dato de referencia un valor entre $8 \mathrm{~g} / \mathrm{L}$ (Maselli e Dierking, 2018) e $9 \mathrm{~g} / \mathrm{L}$ (Licciardello et al, 2011).

\section{I) Expulsión forzada do gas por axitación repetida.}

0 proceso é moi simple, comezando pola pesada dunha lata de $330 \mathrm{~mL}$ de refresco de cola sen abrir e repetindo a pesada da lata xusto despois de abrir. Así coñeceremos a masa do gas que escapa de inmediato na apertura. Asumimos aquí que esa perda é debida unicamente ao $\mathrm{CO}_{2}$ que ocupaba ese espazo libre entre o líquido e o peche da lata, pero tamén haberá certa cantidade de auga evaporada que dependerá da temperatura á que se encontre o refresco. 
Introducimos o contido da bebida de cola da lata nunha botella baleira de plástico e procedemos a súa pesada. Deseguido axitamos repetidamente esta botella para abrila despois deixando saír o gas (hai que ter coidado de que non saia líquido durante esta acción, o que se consegue se a botella ten un volume bastante maior que a do refresco). Repítese esta acción un bo número de veces ata que se observe que apenas se forman burbullas durante a axitación.

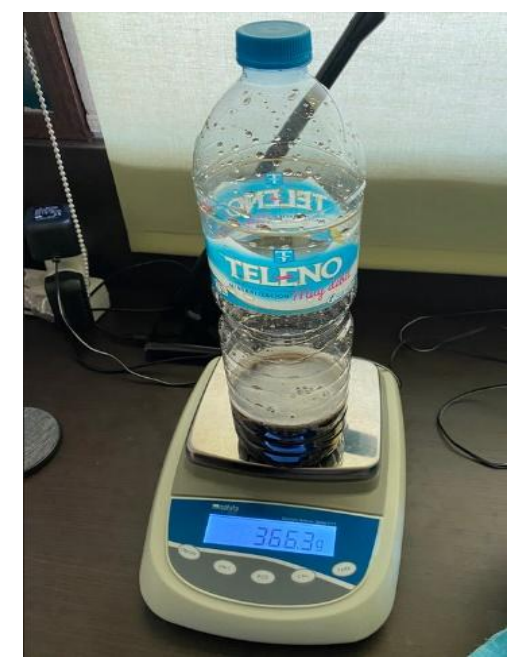

Figura 1. Medida do gas por axitación.

Tamén podemos, antes das pesadas, presionar as paredes da botella de plástico para levar o líquido ata a entrada para así eliminar os gases que están sobre o líquido dentro da botella, por se isto resulta didacticamente máis interesante. Por outra parte, pesar os recipientes baleiros (lata e botella de plástico) tamén permite facer outras aproximacións de cálculo.

Con todo, expresamos deseguido as medidas básicas tomadas da experiencia realizada polos autores deste traballo e que permiten comprender mellor os pasos deste procedemento:

\begin{tabular}{|l|c|}
\hline lata pechada & $356,4 \mathrm{~g}$ \\
\hline lata aberta & $356,2 \mathrm{~g}$ \\
\hline
\end{tabular}

perda gas inicial $=356,4-356,2=0,2 \mathrm{~g}(1)$

\begin{tabular}{|l|c|}
\hline botella + contido inicial & $367,7 \mathrm{~g}$ \\
\hline botella + contido final & $364,8 \mathrm{~g}$ \\
\hline
\end{tabular}

masa de gas liberado por axitación $=367,7-364,8 \mathrm{~g}=2,9 \mathrm{~g}$ (2)

masa total de $\mathrm{CO}_{2}$ na lata $[(1)+(2)]=2,9+0,2=3,1 \mathrm{~g}$ 
Polo tanto, expresando a concentración por litro teremos:

$$
\left[\mathbf{C O}_{2}\right]=3,1 \mathrm{~g} / 0,330 \mathrm{~L}=9,4 \mathrm{~g} / \mathrm{L}
$$

Expresado en molaridade:

$$
\left[\mathrm{CO}_{2}\right]=0,2 \mathrm{~mol} / \mathrm{L}
$$

Como se observa, o valor obtido está dentro do aceptable para o rango 8-9 g/L que mostra a bibliografía, tendo en conta todas as aproximacións e os erros sistemáticos e de operación. En particular, lémbrese que unha parte da perda de masa observada tamén inclúe vapor de auga, polo que os resultados sempre deberán ser maiores dos que se resultarían de só ter en conta a liberación do $\mathrm{CO}_{2}$.

\section{II) Liberación do gas de xeito natural co recipiente aberto}

Este segundo procedemento é tamén sinxelo aínda que máis laborioso, porque implica abrir a lata do refresco e ir vendo como vai diminuíndo a súa masa co tempo. Neste caso, a temperatura é un efecto moi importante a considerar pois inflúe tanto na solubilidade do gas carbónico como no ritmo de evaporación da auga. Por iso, solicitouse ao alumnado que realizase o experimento cunha lata que vai estar permanentemente na neveira e que só se saca dela para realizar as sucesivas pesadas. Deste xeito, dada a baixa temperatura, minimizamos a taxa de evaporación de auga (que introduce variacións no ritmo de descenso dos valores) e aseguramos que a temperatura se manteña constante durante todo o proceso.

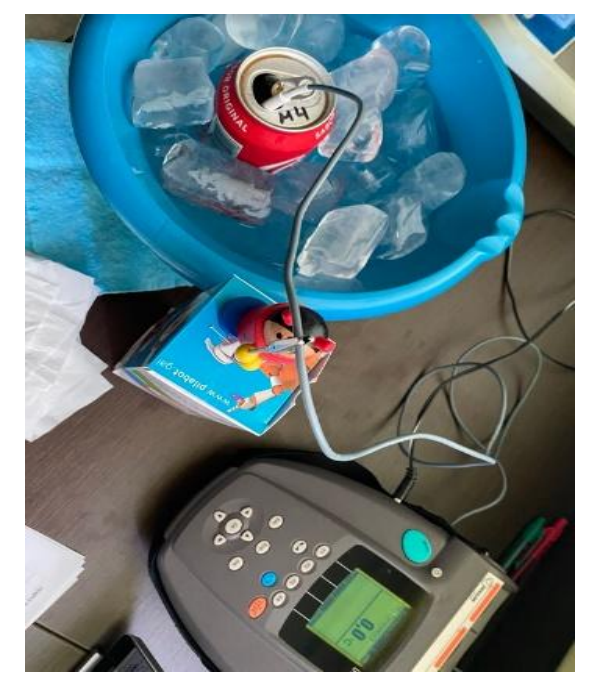

Figura 2. Medida do gas por liberación.

Para este artigo, os autores realizamos o procedemento a tres temperaturas diferentes, sendo unha delas de $0,1{ }^{\circ} \mathrm{C}$ (mantendo a lata do refresco nun baño de auga líquida/xeo). A fin de manter a temperatura ben controlada (engadindo xeo ou auga quente) monitorizamos as temperaturas cun dispositivo VTT, como se ve na figura 2. 
A seguinte táboa mostra os valores ás tres temperaturas de traballo durante as seis primeiras horas, tomando medidas cada media hora, aínda que aquí só mostramos os valores de cada hora, e o valor final despois de 16 horas, pois a partir dese valor non se observaron cambios nas medicións.

Táboa 1. Medida do gas por liberación.

\begin{tabular}{|c|c|c|c|}
\hline $\begin{array}{c}\text { TEMPO } \\
\text { (horas) }\end{array}$ & MOSTRA 1 $\left(12,0^{\circ} \mathrm{C}\right)$ & MOSTRA 2 $\left(42,5^{\circ} \mathrm{C}\right)$ & MOSTRA 3 $\left(0,1^{\circ} \mathrm{C}\right)$ \\
\hline 0 & 355,5 & 354,0 & 357,2 \\
\hline 1 & 354,6 & 351,0 & 356,6 \\
\hline 2 & 354,1 & 350,1 & 356,3 \\
\hline 3 & 353,7 & 349,4 & 356,0 \\
\hline 4 & 353,4 & 348,9 & 355,9 \\
\hline 5 & 353,4 & 348,2 & 355,8 \\
\hline 6 & 353,3 & 347,8 & 355,7 \\
\hline$\ldots$ & $\ldots$ & $\ldots$ & $\ldots$ \\
\hline 16 & 352,9 & 346,2 & 355,3 \\
\hline
\end{tabular}

A fin de comparar o ritmo de liberación do gas axustamos as medidas ao valor inicial da Mostra 3 (que é a que estivo a 0,1 ${ }^{\circ} \mathrm{C}$ ), mostrando o resultado claramente como o ritmo de liberación increméntase coa temperatura como era de esperar.

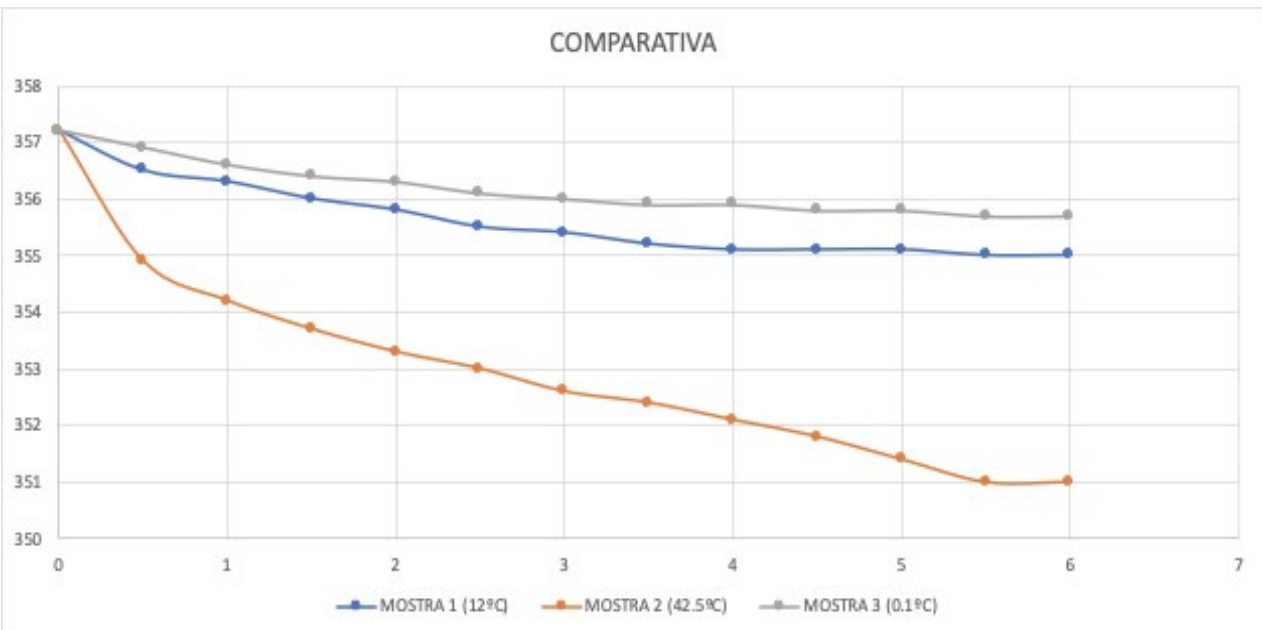

Figura 3. Gráfica comparativa da tasa de liberación de $\mathrm{CO}_{2}$ en función da temperatura e o tempo. 
A fin de obter o resultado buscado debemos ter en conta que segundo aumenta a temperatura da mostra utilizada, ademáis de se incrementar a liberación de $\mathrm{CO}_{2}$, tamén aumenta a perda de masa por evaporación de auga, como xa foi indicado. Para coñecer a cantidade de auga que tamén se liberaba xunto co dióxido de carbono realizamos en paralelo outra experiencia na que introducimos auga nas latas baleiras e ás tres temperaturas de traballo. Deste xeito, aproximámonos á diminución da masa debida unicamente á evaporación da auga, e podemos restar estes valores ás medidas totais realizadas co refresco.

0 resultado desta actividade da os seguintes valores para a masa de auga evaporada:

Táboa 2. Masa de auga evaporada en 16 horas.

\begin{tabular}{|c|c|c|c|}
\hline $\begin{array}{c}\text { Tempo } \\
\text { (horas) }\end{array}$ & $\begin{array}{c}\text { Mostra 1 } \\
\left(12,0^{\circ} \mathrm{C}\right)\end{array}$ & $\begin{array}{c}\text { Mostra 2 } \\
\left(42,5^{\circ} \mathrm{C}\right)\end{array}$ & $\begin{array}{c}\text { Mostra 3 } \\
\left(0,1^{\circ} \mathrm{C}\right)\end{array}$ \\
\hline 16 & $0,8 \mathrm{~g}$ & $4,5 \mathrm{~g}$ & $0,2 \mathrm{~g}$ \\
\hline
\end{tabular}

Tendo en conta os valores que se expresan nas Táboas 1 e 2 chegamos á variación de masa debida á liberación do $\mathrm{CO}_{2}$ para cada unha das tres mostras, e que representamos na seguinte táboa:

Táboa 3. Masa de $\mathrm{CO}_{2}$ liberada en 16 horas.

\begin{tabular}{|c|c|c|c|}
\hline $\begin{array}{c}\text { Tempo } \\
(16 \mathrm{~h})\end{array}$ & $\begin{array}{c}\text { Mostra } 1 \\
\left(12,0^{\circ} \mathrm{C}\right)\end{array}$ & $\begin{array}{c}\text { Mostra } 2 \\
\left(42,5^{\circ} \mathrm{C}\right)\end{array}$ & $\begin{array}{c}\text { Mostra 3 } \\
\left(0,1{ }^{\circ} \mathrm{C}\right)\end{array}$ \\
\hline Variación por liberación total & $2,6 \mathrm{~g}$ & $7,8 \mathrm{~g}$ & $1,9 \mathrm{~g}$ \\
\hline Variación debida evaporación de auga & $0,8 \mathrm{~g}$ & $4,5 \mathrm{~g}$ & $0,2 \mathrm{~g}$ \\
\hline Variación asignada ao $\mathrm{CO}_{2}$ & $1,8 \mathrm{~g}$ & $3,3 \mathrm{~g}$ & $1,7 \mathrm{~g}$ \\
\hline
\end{tabular}

Para obter o resultado buscado utilizamos o valor da Mostra 2 pois é na que se mediu a máxima cantidade de dióxido de carbono liberado.

$$
\left[\mathrm{CO}_{2}\right]=3,3 \mathrm{~g} / 0,330 \mathrm{~L}=10 \mathrm{~g} / \mathrm{L}
$$

Os resultados obtidos nos dous procedementos, 9,4 g/L e 10 g/L, están dentro do esperado (8,0 - 9,0 g/L) tendo en conta os protocolos básicos tidos en conta, os erros de medida, a resolución das balanzas e as aproximacións conceptuais tomadas en consideración.

\section{Outras accións a realizar}

Ademais destas dúas accións presentadas podemos realizar outras actividades, outros cálculos e outros procedementos, dependendo das características do alumnado e do nivel educativo no que esteamos. 
Así, no que se refire aos cálculos, podemos ampliar a expresión de concentración do dióxido de carbono en \% en masa, en fracción molar e mesmo en molalidade. Tamén podemos utilizar o concepto de volume molar para expresar a cantidade do gas en condicións normais de P e T, e mesmo facer cálculos noutras condicións mediante a expresión $P \cdot V=n \cdot R \cdot T$. Un cálculo tamén interesante é obter o valor do número de moléculas que se desprenden na unidade de tempo, conectando masa, moles e Número de Avogadro. Así, no segundo dos procedementos, para a mostra na que menos gas se libera (Mostra 3) obteremos:

$$
1,7 \mathrm{~g} \times \frac{1 \mathrm{~mol}}{44 \mathrm{~g}} \times \frac{6,022 \cdot 10^{23}}{1 \mathrm{~mol}} \times \frac{1}{16 \mathrm{~h}} \times \frac{1}{3600 \mathrm{~s}} \approx 4 \cdot 10^{17} \mathrm{moléculas} / \mathrm{s}
$$

Outras actividades de moito interese teñen que ver con estratexias que están na vangarda didáctica das ciencias experimentais, como son a indagación, o uso de probas e a argumentacion (Jimenez Aleixandre e Puig, 2013). Trátase de abordar mediante esas estratexias cuestións como a relación da temperatura coa solubilidade, se se evapora a igual ritmo a auga se só hai este líquido ou no caso do refresco, se haberá variacións no caso de facelo con versións de refrescos diferentes da mesma marca (normal, light, zero, max, etc.), ou se haberá variación con marcas diferentes... En particular, o cálculo que se presenta no parágrafo anterior dá para unha proveitosa discusión en termos de valorar contextualizadamente o significado do Número de Avogadro.

Finalmente, pódense establecer outros procedementos experimentais con estratexias semellantes pero con outros tipos de líquidos carbonatados como gasosas, cervexas, augas minerais con gas, etc...

\section{CONCLUSIÓNS}

Como se pode observar, trátase dun tipo de actividades moi simples que pode ser levado a cabo polo alumnado de calquera curso de secundaria, e tamén nalgúns de primaria, nas súas casas, adaptándoas ás súas posibilidades. Aínda que aquí aparecen procedementos con diferentes temperaturas, no caso da actividade caseira podemos reducila a un único tipo de mostra que opere ou ben á temperatura da neveira, para manter a constancia das condicións, ou a outro valor de temperatura nun lugar da casa onde haxa pouca oscilación térmica no tempo das medidas.

Hai moitas variacións que se poden introducir para diversificar os procedementos. Así, unha parte dos estudantes poden facer a experiencia con refrescos "light" mentres ca outros o fan coa versión normal, ou se pode facer con outros tipos de bebidas carbonatadas, o que permitirá posteriores discusións e argumentacións en base ao uso de probas, podéndose comparar resultados e tamén establecer melloras nos procesos e valoración dos erros que se cometan.

Finalmente, achegarse a medidas de concentración de disolucións, a cálculos con moles ou co Número de Avogadro, co volume molar ou usando a expresión $\mathrm{P} \cdot \mathrm{V}=\mathrm{n} \cdot \mathrm{R} \cdot \mathrm{T}$, observar a relación entre solubilidade e temperatura, a toma de medidas ou a realización de gráficas, etc, a partir de algo que forma parte da súa vida cotiá, entendemos que xera uns beneficios importantes en termos de aprendizaxe. Isto ten especial importancia para certos contidos que presentan especial 
dificultade para o alumnado como é o concepto de mol e o Número de Avogadro (Furió etal, 2002) ou o modelo cinético-molecular (Oliva, 2003).

\section{REFERENCIAS}

Caamaño, A. (2011). Enseñar mediante la contextualización, la indagación y la modelización. Alambique Didáctica de las Ciencias Experimentales, 69, 21-34.

Caamaño, A. (2005). Trabajos prácticos investigativos en química en relación con el método atómico-molecular de la materia, planificados mediante un diálogo estructurado entre profesor y estudiantes. Educación Química 16(1), 10-19.

Catret, M., Gomis, J., Ivorra, E. e Martínez, J. (2013). El uso del entorno local en la formación científica de los futuros docentes, IX Congreso Internacional sobre investigación en Didáctica de las Ciencias, 749-753.

Furió C., et al (2002). Revisión de investigaciones sobre la enseñanza-aprendizaje de los conceptos cantidad de sustancia y mol. Enseñanza de las Ciencias, 2002, 20(2), 229-242.

García-Molina, R. (2011): «Ciencia recreativa: un recurso didáctico para enseñar deleitando». Revista Eureka sobre Enseñanza y Divulgación de las Ciencias, núm. 8 (número extraordinario), 370-392.

Jiménez Aleixandre, M. P. e Puig, B. (2013): El papel de la argumentación en la clase de ciencias. Alambique. Didáctica de las Ciencias Experimentales 75, 85-90.

Licciardello, F. et al. (2011). Improvement of $\mathrm{CO}_{2}$ retention of PET bottles for carbonated soft drinks. Italian Journal of Food Science. January 2011, 115-117.

Maselli, A. e Dierking, J. (2018). Influencia del $\mathrm{CO}_{2}$ disuelto en la medición de la Concentración en Bebidas Dietéticas. Maselli Measurements, Inc. Parma. https://phelectronica.com.ar/imgs/pdf/Influencia\%20de\%20C02\%20Disuelto.pdf

Oliva, J. M. et al (2003). Un estudio sobre el papel de las analogías en la construcción del modelo cinético-molecular de la materia. Enseñanza de las Ciencias, 2003, 21(3), 429-444. 